\title{
Cidadania, desenvolvimento e dignidade humana: uma releitura da esfera pública arendtiana à luz da solidariedade
}

\author{
Citizenship, development and human dignity: a rereading of arendtian public \\ sphere by the light of solidarity
}

Jailton Macena de Araujo*

\section{Resumo}

A ideia de cidadania deve ser continuamente posta em evidência de modo a se maximizarem os seus contributos à superação da exclusão e desigualdades sociais do contexto da globalização. É necessário, pois, que sejam repensados os elementos que tradicionalmente compõem a esfera pública de modo a se permitir que os direitos abarcados pela cidadania sejam dotados de eficácia máxima, voltados à concreção do desenvolvimento e da dignidade humana à luz da solidariedade que impõe o comprometimento das pessoas entre si e com o mundo.

Palavras-chave: Cidadania. Solidariedade. Esfera pública. Dignidade humana.

\section{Abstract}

The idea of citizenship should be continually brought into evidence in order to maximize their contributions to overcoming exclusion and social inequalities in the context of globalization. It is necessary, therefore, to be rethought the elements that traditionally make up the public sphere in order to allow the rights embraced by citizens are provided with maximum efficiency, focused on the concretion of development and human dignity in the light of solidarity which requires the commitment of people to each other and the world.

Keywords: Citizenship. Solidarity. Public sphere. Human dignity.

\section{Introdução}

Ao se reconhecer a imperiosidade na realização dos direitos correlatos ao direito ao desenvolvimento, reafirma-se a cidadania enquanto instrumento primordial à luta pela sua consecução, que acaba por reverberar e fomentar a ampliação e consolidação desses direitos - civis, políticos, sociais e econômicos - que nele se compreendem.

Nessa medida, a solidariedade deve ser convertida em condição sine qua non para o estabelecimento de uma cidadania transformada e transformadora que estabeleça, a partir dos direitos classicamente assegurados no constitucionalismo, uma nova perspectiva que tenda a fortalecer os mecanismos de luta pela realização da dignidade.

A essa evidência, questiona-se: seria possível reconsiderar a cidadania, sob o prisma da solidariedade de modo a, no contexto da esfera pública, serem reconstituídos os elementos civis, políticos e sociais em torno da ideia geral de bem-estar social, de modo a proporcionar a sua realização?

\footnotetext{
Doutor em Ciências Jurídicas, área de concentração Direitos Humanos e Desenvolvimento, pela Universidade Federal da Paraíba (2016), mestre em Ciências Jurídicas, área de concentração em Direito Econômico, pela Universidade Federal da Paraíba (2011) e graduado em Direito pela Universidade Federal de Campina Grande (2007). Atualmente é professor do Curso de Direito, vinculado ao Departamento de Direito Processual e Prática Jurídica (DDPPJ), do Centro de Ciências Jurídicas (CCJ) da Universidade Federal da Paraíba. Advogado. Associado ao Conselho Nacional de Pesquisa e Pós-Graduação em Direito (CONPEDI). João Pessoa - PB - Brasil. E-mail: jailtonma@gmail.com.
} 
Pretende-se, para tanto, reestabelecer uma discussão acerca do papel da cidadania, compreendida à luz da solidariedade, de modo a reconhecê-la como instrumento de transformação social que possa favorecer ao desenvolvimento e à dignidade humana, capaz de favorecer o desenvolvimento.

\title{
2 A perspectiva do desenvolvimento e da realização da dignidade da pessoa humana no contexto atual: condições e possibilidades
}

No contexto da cidadania, o que se coloca, a partir de 1988, com a Constituição Federal brasileira, são posturas estatais que, direcionadas para um fim específico (aqueles firmados no artigo $3^{01}$ ), têm o condão de nortear e determinar as diretrizes e os fundamentos para a atuação do Estado brasileiro gerando uma transformação social.

Essa transformação social é indispensável para a continuidade e concretização das teorias democráticas, cujo fundamento maior é a união das regras do Estado de Bem-Estar Social no afã de se efetivar a justiça social.

Nessa esteira, a reflexão atual a respeito da organização do Estado não pode deixar de considerar os fenômenos econômicos (mundialização, globalização) nem muito menos os problemas daí advindos, tais como a ampliação das desigualdades regionais, o recrudescimento dos quadros de pobreza e miséria, a exclusão política, intelectual, cultural e tecnológica. Ainda acerca da globalização, Santos (2002, p. 14) preceitua:

\begin{abstract}
A globalização neoliberal corresponde a um novo regime de acumulação do capital, um regime mais intensamente globalizado que os anteriores, que visa, por um lado, dessocializar o capital, libertando-os dos vínculos sociais e políticos que no passado garantiram alguma distribuição social e, por outro lado, submeter a sociedade no seu todo à lei do valor, no pressuposto de que toda a atividade social é mais bem organizada quando organizada sob a forma de mercado.
\end{abstract}

É de se aduzir que a consequência principal desse direcionamento dos vínculos sociais para a lei do valor gera a "[...] distribuição extremamente desigual dos custos e das oportunidades produzidos pela globalização neoliberal no interior do sistema mundial, residindo aí a razão do aumento exponencial das desigualdades sociais [...]". (SANTOS, 2002, p. 14), o que ocorre e se agrava em todas as esferas, seja na comparação entre países ricos e países pobres, seja ainda entre os sujeitos mais ricos e os mais pobres no interior do mesmo país.

As contradições agudas provocadas pela globalização são acentuadas pela hegemonia neoliberal, que põe em embate a democracia política e social, os direitos de liberdade e os direitos sociais. Como reflexo do surgimento, no século XX, dos direitos fundamentais prestacionais, ou seja, direitos que dependem de uma atuação positiva do Estado, que passa a existir a imperativa necessidade de que se forneça à população condições materiais básicas, com o fim de que se atinjam os objetivos socioeconômicos, proporcionando a prerrogativa de que se possa exigir do Estado o seu fomento.

As pressões de grupos sociais organizados, notadamente no Brasil, onde as diferenças sociais são bastante visíveis e o número de excluídos atinge patamares inaceitáveis, tem levado a uma crise sem precedentes, em que a realização dos direitos socioeconômicos é colocada como questão pontual e essencial para que se possa efetivar o direito humano ao desenvolvimento e se torna corolário da luta pela cidadania.

Nessa medida, há de se reconhecer que a evolução da cidadania formalmente considerada para a cidadania material que se propõe é o engrandecimento generalizado do substrato essencial para a vida

1 Nomeadamente, a construção de uma sociedade livre, justa e solidária; a garantia do desenvolvimento nacional; a erradicação da pobreza e a marginalização e redução das desigualdades sociais e regionais; e, a promoção do bem de todos, sem preconceitos de origem, raça, sexo, cor, idade e quaisquer outras formas de discriminação. 
civilizada, que se adquire não apenas equalizando as oportunidades e condições dos mais vulneráveis socioeconomicamente, como também reduzindo os riscos e inseguranças a partir do comprometimento de todos com esse ideal.

Segundo Bottomore (2007, p. 99), nas sociedades capitalistas, "[...] o aumento dos direitos sociais no marco do bem-estar, não transformou de modo profundo o sistema de classes, nem os serviços sociais eliminaram a maioria dos casos de pobreza [...]", o que se viu foi o aprofundamento da ideia de cidadania formal, a ser entendida como o pertencimento a um Estado-nação, sem que isso tenha significado a melhoria das condições de vida das pessoas.

A cidadania meramente formal estabelece um como, mas não um quê, ou seja, não se determina de modo claro o conteúdo real da vivência das pessoas, a despeito das regras para essa vivência estarem todas dispostas. Acontece muitas vezes de se falar do choque entre dois Estados paralelos, em que, de um lado, está o plano ideal do "[...] ordenamento previsto pela constituição, em que as decisões coletivas devem ser tomadas pelos órgãos competentes, com delegação bem definida" e, do outro, "[...] se desenvolveu um novo ordenamento segundo o qual muitas decisões coletivas são tomadas diretamente pelos grupos interessados, mediante acordos fundamentados exclusivamente no reconhecimento do poder recíproco" (BOBBIO, 1991, p. 70-71), ocasionando um choque de realidade que acaba por agravar os problemas sociais daqueles que são os principais interessados na realização daqueles objetivos sociais dispostos na constituição, que são os cidadãos comuns.

A cidadania social, por sua vez, consiste no conjunto de direitos civis, políticos e sociais, cuja definição passa necessariamente pela asseguração dos seus três elementos básicos - civil, político e social, os quais são caracterizados por Marshall (1967, p. 64) nos seguintes termos: (1) elemento civil, formado pelos "[...] direitos necessários à liberdade individual - liberdade de ir e vir, liberdade de imprensa, pensamento e fé, o direito à propriedade, e de concluir contratos válidos e o direito à justiça2"; (2) elemento político, ligado ao "[...] direito de participar no exercício do poder político, como um membro de um organismo investido da autoridade política ou como um eleitor dos membros de tal organismo" (MARSHALL, 1967, p. 64); e (3) elemento social, o qual se refere, nas palavras de Marshall (1967, p. 64) a "[...] tudo o que vai desde o direito a um mínimo de bem-estar econômico e segurança ao direito de participar, por completo, na herança social e levar a vida de um ser civilizado de acordo com os cidadãos que prevalecem na sociedade".

Pode-se depreender, então, que o grande e mais grave problema do nosso tempo no que se refere à cidadania não é mais o fundamento de seu conteúdo, uma vez que todos os direitos reconhecidos como componentes da cidadania estão hoje previstos nas constituições sociais, nas leis e em muitos tratados internacionais, mas sim a proteção e a garantia desses direitos. Proteção que significa, acima de tudo, aceitar a constatação de que já se conseguiu, no plano normativo, implantá-los, mas no plano fático muito ainda precisa ser feito para que os direitos que compõem a cidadania sejam dotados de eficácia.

Assim, a cidadania, mantém intacta a sua raiz normativa fundamental, muito embora sua construção social ainda se mantenha alijada. Isso exige, então, da sociedade e do próprio Estado, como promotor do processo de emancipação social, pautado na solidariedade, que os avanços sociais, dos quais resulta o diálogo social, sejam operados no sentido de limitar os fluxos de riquezas para os mais ricos, no sentido de promover a redistribuição dos bens que compõem a herança social. É nesse sentido que se pode afirmar que a função dos direitos, que compõem cada um dos elementos da cidadania, devem ser orientados para a criação, manutenção, distribuição e redistribuição das condições para a implementação das condições fáticas para sua efetiva realização (BERTASO, 2012, p. 3885).

A grande questão é, portanto, garantir à cidadania eficácia e aos seus elementos (civis, políticos e sociais), cuja realização consagra de modo claro os ideários históricos de liberdade, igualdade e fraternidade

Segundo o autor, o direito à justiça refere-se ao direito de defender e afirmar todos os demais direitos, em termos de igualdade, em face do devido acompanhamento processual. Assim, ao elemento civil liga-se, como instituição mais importante, aos tribunais de justiça. 
dos direitos humanos. A esse respeito, Bloch (2011, p. 278) assevera que as palavras "liberdade, igualdade e fraternidade" apontam na direção de uma liberação que, ao fim, vincule o homem a si mesmo, a sua suscetibilidade de desenvolvimento, que proporciona o incremento da liberdade de ação e que resulta ativamente da luta sócio-política, sendo reconhecida como um conceito relacional, que revela a ausência de privação, portanto, a "liberdade de algo".

No que se refere à liberdade, não se pode admiti-la sem que se cumpram os direitos sociais e econômicos, cuja efetivação exige uma prestação positiva do Estado, relacionando-a, pois, à igualdade. A eficácia social reduzida dos direitos econômicos e sociais não se deve absolutamente à ausência de previsão legislativa. O grande desafio de realização de um Estado de Bem-Estar Social pleno, preocupado com o desenvolvimento e com a promoção da dignidade humana, está na inserção desses problemas na agenda política dos governos, na formulação das estratégias de atuação, na implementação das ações, na avaliação das atividades implementadas de modo a retroalimentar o processo de formulação das políticas públicas e na composição dos gastos e orçamentos dos entes federados.

Nessa medida, a Constituição Federal de 1988 ampliou significativamente o campo dos direitos e garantias fundamentais, estando inserida entre as constituições mais avançadas do mundo no que concerne à proteção da pessoa humana. De conformidade com essa abordagem, as normas constitucionais devem ser consideradas em seu conjunto como integrantes de um sistema unitário dotado de força vinculante e diretiva para toda a ordem jurídica, e em razão disso é que se afirma que o direito positivo deve ser efetivado e vivenciado agora, e não apenas num futuro distante e improvável, de modo a fazer valer esses valores que foram postos na norma jurídica.

A exteriorização do novo conceito igualitário (perante a lei) - que não olvide a desigualdade inerente à sociedade de classes - é desafio profícuo a ser superado através de evolução paulatina da dimensão de cidadania que incorpora os direitos políticos, econômicos, sociais e culturais, difusos, coletivos, etc., à medida que se constata que, com o crescimento industrial do século XIX, a sociedade se torna cada vez mais complexa e com problemas cada vez mais graves.

Tais propósitos devem ser tornados realidade sob pena de se responder afirmativamente ao questionamento de Silveira (2001, p. 117): “[...] Cidadania é apenas a formalização jurídico-institucional de direitos?". Na realidade, a cidadania é a efetiva vivência, por todos os cidadãos, dos direitos normativamente assegurados.

É evidente que nem todos os sujeitos sociais desfrutam igualmente do acesso à cidadania. Privase a pessoa desse atributo restringindo-se o campo de sua liberdade e do seu desenvolvimento. Nessa medida, a igualdade deixa te ter um plano principal, exigindo-se que, para que haja a sua realização, haja como elemento primordial a solidariedade em prol da realização da cidadania para todos (o que dá a tônica à democracia).

O conceito de democracia exige que os cidadãos tenham a possibilidade efetiva de utilizar aquelas regras dispostas pelo Estado, para isso deve ser mantido um patamar de igualdade social entre as pessoas, além, é óbvio, que os mecanismos institucionais sejam verdadeiramente democráticos.

A democracia é, portanto, direito objetivo e subjetivo, cuja titularidade deve ser exercida por todos do povo. Sem ela, como já mencionado, os demais valores seriam despidos de conteúdo, a convivência, o consenso, o pluralismo, a dignidade e as liberdades jamais alcançariam a importância e a perfeição que ora assumem no rol de direitos da pessoa humana.

A atuação política, desse modo, tem sido relegada da ideia de fim em si mesmo, passando a estar a serviço da mera formalização dos direitos de cidadania. O que deve ficar claro é que a cidadania apenas formalmente considerada tem apenas o condão de esvaziar o ser humano de sua dignidade, em vez de emancipá-lo e conduzi-lo pelos caminhos do desenvolvimento.

Como assevera Clarke (2010, p. 41), essa ideia de cidadania universal e formal apenas atribui aos povos as características genéricas que decorrem dos três elementos de cidadania formal, sem sequer 
influir na vida das pessoas. A cidadania acaba encarada como uma mera abstração que passa ao largo das

[...] verdadeiras identidades da vida real; ignora aspectos como o gênero, a raça ou a orientação sexual, por mencionar alguns. Se centra nas categorias políticas mais genéricas, umas categorias que, devido a sua generalidade e a sua universalidade, deixam de ter sentido político ao estar distantes da realidade.

Ser cidadão, nessas condições, é apenas uma condição jurídica que não emancipa nem beneficia o ser humano. A emancipação, vislumbrada ante os mecanismos apartados da cidadania, é convertida em uma quimera, que acaba convertendo o agir político e social em um mecanismo para sujeitar as pessoas. A convivência humana é uma ideia que promete o desenvolvimento das capacidades da pessoa humana, mas, para que essa promessa possa se cumprir, deve ser superada antes a tradicional distinção entre emancipação e cidadania formal, que exige uma nova racionalidade pautada na solidariedade.

A racionalidade, antes entendida como econômica, passa a ser entendida, no contexto constitucional de dignidade humana, sob o ponto de vista da solidariedade, que deve conduzir a atuação estatal, orientando a representação normativa dos desejos dos cidadãos e configurando uma realização prática daquilo que é posto na norma enquanto anseio social e que transmuda a cidadania formal - composta pela previsão normativa dos direitos que compõem os elementos civis, políticos e sociais - em cidadania sob a acepção da solidariedade ou do comprometimento mútuo em torno da efetivação dos direitos. Reforçando essa ideia de solidariedade e comprometimento, Clarke (2010, p. 12) adverte:

Ser cidadão pleno significa participar tanto na direção da própria vida como na definição de alguns de seus parâmetros gerais; significando ter consciência de que se atua em e para um mundo compartilhado com outros e de que nossas respectivas identidades individuais se relacionam e se criam mutuamente. Ser cidadão pleno significa empenhar-se em realizar o compromisso com o mundo, com compromisso, um compromisso reencantado com o mundo.

Há de se reconhecer que a cidadania, numa perspectiva solidária, é essencial à integração e permanência do corpo social e também à personalidade individual, gerando frutos positivos, uma vez que liga o homem à sociedade (Santo Agostinho advertiu que um povo é feito de homens unidos no amor a alguma coisa). Assim, a cidadania solidária se projeta espontaneamente no mundo como seu único domínio verdadeiro por decorrer da vontade e da convivência humanas.

Por essa razão, a cidadania deve ser encarada ainda como competência de tomar consciência crítica, que se inicia com a educação emancipatória, mas apenas pode se tornar instrumentalizada com a educação, com o trabalho e com a participação no processo de desenvolvimento, capaz de fazer arrefecer as desigualdades sociais postas como face da exclusão política.

\section{Apontamentos acerca da ideia de cidadania: contextualizando o problema}

Tradicionalmente, a cidadania é compreendida como decorrência lógica de um Estado democrático de fireito, e justamente por ser composta de uma multiplicidade de pessoas, deve permitir que as decisões políticas, por se refletirem nos interesses e na vida de todos, sejam tomadas na esfera pública, quer diretamente, quer por meio de representantes eleitos.

Na sistemática jurídica corrente, tudo o que é positivado é considerado válido, mas há, sem dúvidas, uma diferença entre mundo da validade e da facticidade. O válido tem existência externa na ordem jurídica, o que oferece a compreensão e a sensação do assentamento na realidade daquilo que é posto na lei, entretanto o mais importante é o intento de deduzir e valorar o direito positivo a partir do ponto de vista de uma vontade normativa direcionada a uma finalidade, na qual os atos criadores do direito são tidos tão somente por seletivos, orientados segundo necessidades prático-empíricas que se fundam na realidade, embora não necessariamente possam gerar consequências nessa realidade. 
No plano da facticidade, o que é válido por simplesmente estar posto na letra da lei sai dos limites do papel e se impõe na realidade social, no meio das pessoas, de modo a produzir efeitos reais que tencionam a condução, modificação ou conformação das ações sociais em torno de objetivos normativos e reais que se conjugam em benefício das pessoas, que não são um mero ideal.

A realização da pessoa, a despeito de se verificar a partir de uma construção sócio-política, decorre de mera existência e do nascimento, o que condiciona, desde então, a aquisição da cidadania como pressuposto para a realização do fim maior que é a dignidade da pessoa humana, o que não ocorre no plano meramente normativo.

É clara então a necessidade de que o sujeito jurídico, que, embora seja destinatário dos direitos, os detém apenas no aspecto da validade - que conferem, formalmente, cidadania - seja também um sujeito real, dotado de prerrogativas garantidas na lei, postas em prática através daquilo que foi definido pelos mecanismos democráticos para a condução de sua vida e para a realização dos objetivos e dos anseios que direcionam o ser humano para a concretização da dignidade.

Todo ser humano depende de elementos externos disponibilizados pela construção políticonormativa que the permitem inserção na vida social e política, tornando-o integrante do Estado a partir dos parâmetros da cidadania que condicionam a sua vida enquanto ente politicamente inserido, na qual "[...] tudo aquilo com o qual eles [os seres humanos] entram em contato, torna-se uma condição de sua existência." (ARENDT, 1983, p. 17).

O tipo elementar de representação cidadã se coloca como uma correlação entre o agente e os representantes públicos, o que se estabelece não em benefício dos cidadãos, mas em benefício daqueles que são detentores do poder.

Observa-se que a ideia de sociedade politizada, em que há o exercício real da cidadania, deve ser articulada como condição da representação, na qual se produza uma representação em que os cidadãos estejam inseridos em dois movimentos básicos, de erupção e de prorrupção social respectivamente, definidas pelo autor como formação e articulação da sociedade em torno da ideia de participação política.

Essa compreensão afasta e contradiz o ideário histórico da cidadania, pautada no liberalismo, o qual contribuiu com a formulação de uma ideia de cidadania universal, em que se afirmava, ao menos formalmente, que todos os indivíduos nasciam livres e iguais, o que acabava por reduzir a cidadania a uma mera condição legal que propunha direitos que o indivíduo não poderia reclamar do Estado, existindo apenas no plano normativo da validade.

É claro que essa compreensão de cidadania está relacionada ao ideário liberal que tem no capitalismo a sua ideologia de base. O liberalismo se acha penetrado pela excelência da combinação de palavras, em que, de um lado, estava disposta a contraposição ao Estado-polícia; e, do outro, a ordem estamental fundada nos privilégios. A igualdade formal, e apenas formal, de todos ante a lei era considerada a pedra de toque do capitalismo, que estava interessado na generalidade igual para todos da regulação jurídica. O capitalismo interessa-se, assim, de igual maneira na formulação precisa e na asseguração das normas jurídicas como mecanismo de manutenção do status quo.

Outra característica importante dos ideais liberais é vinculada ao precedente do individualismo que estabelece o ser não como cidadão vinculado aos demais, mas como competidor, já que o surgimento da ideia de cidadania, no contexto do liberalismo, começou em sociedades comerciais capitalistas e, por essa mesma razão, apenas poderia ter como fio-condutor os ideários de instituições sociais e econômicas que Ihe deram forma.

Em face dessa compreensão, obviamente ultrapassada de cidadania ${ }^{3}$, é que se faz necessário que seja concebida uma pauta que tome em consideração outros aspectos da cidadania, que leve

\footnotetext{
Aqui se faz referência à compreensão de cidadania como pressuposto exclusivo da acumulação de riquezas, na qual apenas eram admitidos à vida pública os proprietários de terras aos quais se garantia o exercício da vida política.
} 
em consideração não apenas o laço político que vincula os indivíduos, mas também os elementos de identificação que os reúnem em torno de objetivos comuns, que levem em consideração a linha tênue entre o público e o privado na condução da vida política e social.

Ao se considerar a distinção entre a esfera pública e a privada da "vida ativa" do cidadão - que é também um conceito sobre a qual Hannah Arendt (1983, p. 260 ss.) se debruça, afirmando ser o meio através do qual o homem, através do trabalho, estabelece contato com os demais sujeitos -, vem à tona a discussão acerca da ideia de liberdade que circunda suas ações enquanto sujeito componente dos destinos da comunidade. O cidadão não deve ser limitado em sua liberdade, a não ser quando necessário para a liberdade dos demais, mas não se pode olvidar que, numa sociedade de mercado pautada em inúmeras dependências não visíveis, o indivíduo não poderia ser, em absoluto, ator de suas ações. Conquanto, dada a permanente dependência econômica, a liberdade de ação resta impedida para a maioria das pessoas.

A esfera pública deteria, então, um papel mais relevante quanto ao exercício da cidadania, pois compreenderia o espaço da aparência, cuja percepção do outro decorre da visibilidade e da presença de outros sujeitos iguais, não apenas segundo o formalismo e subjetivismo dos direitos individuais, mas, sobretudo, pela presença constante da ação humana que cria e mantém - na criação de instituições políticas democráticas - um mundo em comum.

Esse mundo em comum abriga inúmeros sujeitos sociais que necessitam em medidas diferentes de mecanismos que possibilitem a realização da cidadania em consonância com as perspectivas de sua própria vida. No liberalismo, a compreensão de perspectivas seriam restritas ao quanto cada sujeito possui em propriedade, impedindo-o de realizar-se na esfera pública de modo pleno, restringindo-se lhe a capacidade de usufruir da liberdade.

A concepção clássica de liberdade é identificada com a teoria kantiana de que cada um tem o direito de buscar a realização dos seus próprios anseios, desde que essa busca não interfira na liberdade dos outros sujeitos de perseguirem o mesmo fim de liberdade para a realização de sua felicidade, em consonância àquilo que é permitido na lei. "Este direito à liberdade pertence a cada membro da comunidade como ser humano na medida em que cada um é um ser capaz de possuir direitos (NUSSBAUM, 2012, p. 47)".

A liberdade apenas se faz possível em decorrência da indeterminação dos aspectos da condução da própria vida no mundo, portanto, por suas inúmeras possibilidades - que detém a características da irreversibilidade e da imprevisibilidade (ARENDT, 1983, p. 242 ss.), o sujeito age de modo a produzir resultados relacionados à vivência e à construção de seus objetivos particulares. A liberdade é o alfa e o ômega na compreensão da realização da cidadania, consistindo numa "[...] porta aberta do homem consigo mesmo, na qual não há nada alheio ao homem, nenhuma alienação, nenhuma coisificação" (BLOCH, 2011, p. 295-296).

Quando se percebe que a cidadania se coloca como mera utopia dirigida à condução da tentativa de realização do sujeito, fica cada vez mais denso o contraste entre a validade e a facticidade, que acabam por exsurgir também dentro dos governos democráticos, onde o sistema das relações legais se choca continuamente com o sistema das relações reais, na qual, muitas vezes, os direitos e garantias estabelecidos no plano constitucional pouco ou nada se refletem no âmbito das relações sociais.

O poder e a individualidade acabam por sobrepor qualquer necessidade mínima dos sujeitos sociais que são reduzidos em sua cidadania a uma mera vinculação a um ente despersonificado - que é o mercado - que detém, efetivamente, a direção da vida de todos, tornando-os meros objetos econômicos. Revela-se, pois, uma verdadeira ditatura da maioria (ou dos poderosos), na qual a imposição dos interesses de uma elite econômica dominante sobrepõe e contraria os verdadeiros interesses sociais coletivos, cujo mecanismo democrático, "[...] se converte em um ostracismo ideológico. Uma parte da população, suficientemente homogênea, seria capaz de impor, sem a mediação do confronto argumentativo parlamentar, o exílio interno dos dissidentes minoritários" (SANTOS, 2007, p. 10). 
Nesse contexto, pode-se apontar que o pensamento liberal, embora, como se disse, historicamente tenha condicionado a ideia de cidadania aos elementos do capitalismo, limitando a realização de muitos dos sujeitos sociais, ainda tem muito a dizer acerca do objetivo de uma maior participação, tanto individual quanto compartilhada, seja na experiência da vida própria, seja na conformação das condições gerais da mesma, haja vista que as ideias liberais não estacionaram. Pelo contrário, evoluíram em busca de uma tônica cada vez mais democrática, que acaba por apropriar a cidadania enquanto um sentimento de inserção sócio-política (como se discutirá adiante).

A cidadania deve ser compreendida então como um animus, um sentimento que perfila o sujeito fazendo-o com que se sinta empoderado de um sentimento que o compele a participar dos processos sociais que ocorrem a sua volta e dizem respeito ao seu futuro e ao futuro da sua comunidade. Nessa construção do ser, por assim dizer, o sentimento de cidadania repercute na compreensão social do indivíduo, em que o bem-estar coletivo é mais importante do que o bem-estar individual, e onde as características do respeito e da independência devem ser desenvolvidas enquanto atributos inerentes à cidadania e aceitos também como deveres públicos e privados ante os demais cidadãos.

Como reflete Bloch (2011, p. 277), "o homem está dentro de sua própria pele, o mesmo se se sente bem que se se sente mal nela. Em todo caso, é a sua, e dentro destas quatro paredes, se assim se pode dizer, vive sua vida privada". Para que possa aparecer na vida pública como sujeito de direitos capaz de reconhecer a realidade do homem, o sujeito deve estar dotado de possibilidades que o conduzam a uma vivência digna.

Entretanto, paira ainda sobre a realidade hodierna a ideologia individualista, na qual o Direito não trata de seres sociais, mas de indivíduos, ou seja, de homens que se bastam a si mesmos enquanto depositários da razão e da possibilidade de acumular bens. Dessa ideia resulta a concepção de que o Estado deve estar voltado à realização do homem enquanto ser individual, e deve ser extraído, ou deduzido, das propriedades e qualidades inerentes no homem, considerado como um ser autônomo, independente de todo e qualquer vínculo social ou político, estando os indivíduos em primeiro lugar em relação aos grupos ou relações que são por eles constituídas.

Nessa medida, a atuação do ente político deve ser voltada para a realização dos fins públicos, uma vez que o Estado "[...] é a personificação da ordem jurídica em sua totalidade e, portanto, de todas as proposições jurídicas que procedem de uma fonte comum, a saber a legislação." (BLOCH, 2011, p. 269) que tem (ou deve ter) como fim maior a realização da pessoa humana em torno da realização da dignidade da pessoa humana e da igualdade cidadã.

O vínculo estreito entre as ideias e valores (aspectos cognitivo-existenciais e normativos) que incluem a ideia de individualismo e de solidariedade são claramente reconhecidos sob o prisma da orientação individual ou coletiva para os valores, incluindo ideias e crenças sociais que envolvem obviamente o quadro complexo da concepção da sociedade. Supõe-se então que se apresenta um quadro de valores que coloca, dentre outros, a solidariedade, estabelecendo uma organização hierárquica que tende a ultrapassar os valores individuais que egoisticamente são idolatrados por cada um dos indivíduos.

Na prática, o que ocorre é que a voracidade do mercado acaba por aniquilar completamente os valores minimamente voltados para a pessoa, reduzindo-os a ideais meramente formais, em que os fins são reduzidos a meios, passando-se a negar a existência dos valores intrínsecos que consideram o ser humano como portador de dignidade.

Seria possível, então, construir uma passagem entre a ideologia de mercado, prevalecente, que separa os valores da realidade fática, de modo a restabelecer os valores como imbricados à realidade do mundo? A melhor resposta segue sendo a de Dumont (1985, p. 269), para quem:

[...] a concepção do homem como indivíduo implica o reconhecimento de uma ampla liberdade de escolha. Alguns valores, em vez de emanarem da sociedade, serão determinados pelo indivíduo para seu próprio uso. Por outras palavras, o indivíduo como valor (social) exige que a sociedade 
Ihe delegue uma parte de uma capacidade de fixar os valores. [...] o valor está imbricado na própria concepção de ideias.

Mencionada ideia vai de encontro ao pensamento de Sen (2005), para quem a liberdade apenas pode ser considerada em sua plenitude quando todas as possibilidades do indivíduo, reais, e não apenas formais, corporificam-se em desenvolvimento que produz mais realização e melhores condições de vida, e, portanto, promove liberdade.

Como se pode depreender, o grau de liberdade dado a cada um dos indivíduos de uma sociedade é proporcional ao número de indivíduos livres, o que acaba por implicar, necessariamente, que todos os indivíduos sejam considerados como detentores de igual valor, com a mesma exigência de liberdade. Entretanto não se pode esquecer que a emancipação ou o grau de liberdade que coloca o indivíduo como detentor de valores, capaz de adentrar no âmbito da concreção da cidadania é ainda uma utopia, pois nem todos detêm os meios para usufruir dessa liberdade, que só se verifica em uma inclusão real, que é possível apenas através da educação e do trabalho.

\section{Cidadania solidária: uma releitura arendtiana da esfera pública à luz da solidariedade}

A ponderação de determinados aspectos da realização da cidadania material, e não apenas formal, liga-se fundamentalmente ao reconhecimento da imprescindibilidade da busca pela igualização dos sujeitos sociais enquanto resposta positiva às determinações de solidariedade inseridas na ordem jurídica com o intuito de favorecer o desenvolvimento humano.

Nesta senda, a ideia de solidariedade deve ser analisada sob o ponto de vista mais amplo possível, compreendendo, além do elemento geográfico, que deve ser o mais vasto, também a maior proporção de seres humanos do planeta. Desse modo, a inquietação com a cidadania apreendida nas três acepções de Marshall, em seus elementos civil, político e social, faz despontar a necessidade de realizar, com carga máxima de eficácia, os direitos constitucionalmente estabelecidos, cujo conteúdo é voltado para a realização da justiça social e para a promoção da dignidade, consoante os preceitos de cidadania solidária, uma vez que a percepção da realidade depende da existência de uma esfera pública ${ }^{4}$ na qual o homem passa a interagir e influenciar, pois a "[...] presença de outros que veem o que vemos e ouvem o que ouvimos garante-nos a realidade do mundo e de nós mesmos" (ARENDT, 1983, p. 60).

A cidadania deve ser vislumbrada numa perspectiva solidária então, em seu aspecto jurídico, referindo-se ao papel do meio social na realização da dignidade da pessoa, pressupondo a luz intensa da esfera pública, na qual, dentre outras coisas, a ação do Estado funciona como imperativo para tornar os homens mais iguais e mais cidadãos. Enquanto princípio social, a cidadania solidária exige a ação de todos em prol do bem comum, posto que a sua concretização contribui para o desenvolvimento integral do ser humano.

A essa evidência, a solidariedade deve ser encarada como comprometimento mútuo de todos em prol da cidadania. Assim, consoante assevera Bertaso (2004, p. 230), pretende-se alcançar, a partir da reconstrução da cidadania "[...] a solidariedade ao sujeito de direitos humanos internacional, na sua concreta condição de sujeitos de igual dignidade, ao contrário de uma solidariedade grupalística que ideologicamente amalgamou a cidadania a uma identidade étnico-cultural”.

\footnotetext{
Depreende-se da ideia de público um significado próprio, derivado das reflexões de Arendt (1983, p. 62), cujo significado se confunde com o próprio mundo, "[...] na medida em que é comum a todos e diferente do lugar que nos cabe dentro dele". Isso expressa uma ligação muito íntima e, ao mesmo tempo, muito forte entre todos os sujeitos, quando trazidos à esfera pública pelo nascimento cidadão ou segundo nascimento arendtiano, em que a solidariedade "[...] tem a ver com o artefato humano com o produto das mãos humanas, com os negócios realizados entre os que, juntos, habitam o mundo feito pelo homem", uma vez que o agir e o discurso humano conferem a inserção de cada um dos homens na esfera pública, confirmando e assumindo o aparecimento físico original, que lhe confere a dignidade pela identidade de cada um com o todo social.
} 
Estabelecida, enquanto elemento intrínseco à cidadania, a solidariedade, exige que os padrões mínimos de bem-estar social sejam alcançados, como um dever estatal que se impõe não apenas às instituições, mas a cada sujeito social que compõe o Estado5. Como bem reflete Clarke (2010, p. 72), a solidariedade impõe que se esteja comprometido como cidadão pleno, o que significa estar comprometido com o mundo.

Com efeito, o Estado brasileiro, em decorrência das condições de subdesenvolvimento, não chegou a construir um Estado de Bem-Estar Social, pautado na cidadania quando estabeleceu a construção de uma sociedade solidária, conquanto o princípio da solidariedade se coloque como legitimador das ações que tem como propósito compensar situações de injustiça histórica de discriminações sofridas por determinados grupos ou minorias em razão de sexo, raça, crença ou situação econômica.

Por esse prisma, é compreensível a afirmativa de que a consecução da submissão do poder estatal à hierarquia da lei, numa perspectiva solidária, só foi possível com a estruturação do Estado de bemestar social, cujo modelo é originário das transformações revolucionárias postas em prática no século $\mathrm{XX}$, especialmente as que passaram a atribuir ao Estado responsabilidades no sentido de promover o desenvolvimento econômico e social.

Partindo dessa compreensão, entende-se que as normas jurídicas determinantes da redução das desigualdades regionais e sociais, da erradicação da pobreza, bem como da realização do desenvolvimento, deixam de ter o simples status de regra jurídica para comportar imensa carga valorativa, dotada de conteúdo positivo que exige atuação comprometida com a sua realização. E é através da cidadania solidária que se possibilita a participação na própria vida e na contínua criação das condições gerais nas quais o ser se desenvolve, tornando-o apto e consciente para essa participação.

A cidadania enuncia essa promessa, mas também oculta a possibilidade do seu fracasso, quando não realizada em condições de dignidade e de respeito aos direitos mínimos do cidadão. $O$ fracasso da cidadania pode ocasionar, no lugar da emancipação, a conversão em um instrumento que neutraliza politicamente um grupo de milhares de pessoas.

É nesse contexto que a solidariedade é inserida na ideia de cidadania, de modo a impedir que ocorra a destruição da participação cidadã e compelindo o Estado e cada um dos cidadãos, comprometidos com a cidadania de todos os demais, a expandirem a cidadania na esfera pública sob o prisma da solidariedade, tornando possível uma pluralidade plena que enseje a construção compartilhada do desenvolvimento como liberdade.

A cidadania oferece muito como ideal e como promessa, mas, para que seus ideais e promessas possam se cumprir, é necessário conhecer os problemas que decorrem de sua configuração. Formalmente, a cidadania é vislumbrada como direito de integração a uma comunidade política, mas foi historicamente ampliada à acepção social que insere os direitos civis, políticos e sociais na sua definição.

Ocorre que, num contexto de desigualdades como o brasileiro, muitos são os problemas a serem enfrentados para que a cidadania seja plenamente realizada, o que se pode afirmar, sem sobra de dúvidas, é que para corrigir esses problemas, "[...] deve-se acometer uma re-conceituação da noção de cidadania, que ainda ambiciosa, não está tão relegada de nossa atual situação social e política como resultado inalcançável" (CLARKE, 2010, p. 34), mas que deve passar necessariamente por uma aproximação com a solidariedade.

A ideia de solidariedade gera uma inteligência e uma racionalidade voltadas para o próprio ser humano, na qual a dignidade humana ganha um respaldo ético, plenamente igual e independente do lugar onde se encontre o ser. A sociabilidade humana, na qual uma vida digna significa uma vida organizada em

Na realidade, as funções do Estado se imbricaram de tal modo que a sua abrangência perpassa quaisquer classificações levadas a intento na perspectiva atual, muito embora se possa afirmar, com certa tranquilidade, que a compreensão atual de Estado é muito mais complexa do que se pode pretender descrever, por essa razão não se pretende nesse espaço aprofundar a discussão. 
comum com outros, passa a ser considerada e respeitada a partir do ideal de dignidade e das múltiplas necessidades humanas. As necessidades humanas são então consideradas parte da própria vida comum (na esfera pública) e servem como elemento de pauta para a promoção do bem-estar social de todos, no sentido de promover a satisfação das necessidades mínimas, não apenas do indivíduo considerado em si mesmo, mas também de todos os sujeitos, especialmente os mais vulneráveis (acabando com a fome, a violência e o tratamento desigual no âmbito político).

Acrescenta-se, então, que a cidadania não é apenas a configuração do direito a ter direitos, como aduzia Arendt, mas também que esses direitos sejam realizados e, mais ainda, que para a realização desses direitos, todo e qualquer cidadão, bem como o Estado e os sujeitos de mercado, estejam comprometidos com a sua realização. Isso é a cidadania solidária: todos são responsáveis pela realização da cidadania de cada um.

O ideal solidário, como se pode perceber, identifica-se à ideia de fraternidade, como corolário histórico dos direitos humanos, ao lado da liberdade e da igualdade, acerca da qual Bloch (2011, p. 296) assevera que o "[...] ideal de fraternidade nasce da doutrina de filiação comum em Deus, que é adicionada a ideia de igualdade, que tem como base um amor familiar universal, mas que tem que se colocar concretamente frente ao próximo".

É no marco dessas mudanças paradigmáticas que se faz necessário que o novo papel da cidadania seja pensado. "Estar comprometido como cidadão pleno é estar comprometido com o mundo" (CLARKE, 2010, p. 27). Devendo ser apontado que a cidadania não é mais fruto meramente da previsão de direitos que gera, em tese, inserção e emancipação, mas condição desta emancipação e do comprometimento em torno da cidadania comum, na qual todas as questões decorrentes das correlações integração e exclusão, desenvolvimento e desigualdade se transformem e estruturem, nas condições socioeconômicas que mais gerem benefícios aos sujeitos sociais.

Concebe-se, nesse contexto, consoante os ensinamentos de Leca (2012, p. 32), que a cidadania solidária é o conjunto ideal de três características: (1) a condição jurídica que confere direitos e obrigações em relação à comunidade política; (2) a divisão clássica proposta por Marshall, na qual a cidadania é dividida nos elementos civil, político e social; (3) o conjunto de funções específicas, que são responsáveis por colocar cada cidadão, sem importar qual a sua categoria social, integrado à lealdade para com as instituições universais, comprometido com os interesses e assuntos públicos que dizem respeito a cada e qualquer cidadão.

Para que o cidadão possa escrever a sua história de modo a ser protagonista de sua própria vida como um cidadão pleno, deve fazê-lo a partir do compromisso com a realidade do eu, dos outros e do mundo. Essas três dimensões estão indubitavelmente entrelaçadas como condição do ser no mundo. A cidadania plena se preocupa pelas três dimensões, atendendo ao eu, aos outros e ao mundo. As mesmas não podem separar-se por completo. Tampouco é fácil identificar que é o que pertence propriamente a cada uma delas (CLARKE, 2010, p. 133).

Desta reflexão fica claro o ideário de cidadania solidária, que implica um senso de coletividade respaldado no sentimento de pertencimento direto a uma comunidade, que é comum a todos, e é derivada do compromisso de respeito a um grupo que se firma tanto nos interesses do sujeito individualmente considerado (agregando-se valores material, político e cultural) como também nos interesses coletivos, permitindo a uma quantidade cada vez maior de pessoas sem poder social adquirir uma maior capacidade de agir politicamente e meios de defender seus interesses e efetivar os seus direitos com maior eficácia possível.

A cidadania solidária "é uma expressão da procura de justiça pelo homem, de seu interesse pelos oprimidos e de seu otimismo no sentido de que a razão e humanitarismo poderão levar e levarão a um mundo melhor" (CHRISTENSON et al., 1974, p. 337), se colocando, portanto, como contraponto da cidadania formal, assumindo que "[...] a existência [de cada cidadão] é política no sentido de que o 
compromisso consigo mesmo, com os outros e com o mundo faz que a existência seja uma existência compartilhada" (CLARKE, 2010, p. 28-29).

Evidencia-se, portanto, que a cidadania solidária, muito mais do que a mera previsão e realização de um rol de direitos, depende da mobilização autônoma dos sujeitos sociais em prol de interesse coletivos, revelando a expressão de um pluralismo social, com a participação comum nas decisões políticas, que vai muito além de uma devoção aos símbolos normativos configurados no texto da lei.

Para a construção da sociedade emancipada e atuante, não se pode esperar que o direito seja mera compilação de vontades sociais que não têm a possibilidade de se concretizar. Os direitos sociais devem ser encarados como formulação social que visa defender o presente, além de esboçar uma realidade futura, antecipando um porvir. Portanto, os direitos que são positivados devem ser efetivados e vivenciados agora, e não apenas num futuro distante ou improvável.

Nesse contexto, Chaui (2007) esboça alguns apontamentos que podem ser considerados quando se apropria da ideia de cidadania solidária a qual se mencionou, apontando a necessidade de ampliação dos debates sobre a representação e vinculando a mais ampla cidadania a três níveis principais, os quais podem ser definidos: na exigência do estabelecimento de uma ordem legal democrática; na exigência do estabelecimento das garantis individuais, sociais, econômicas, políticas e culturais; e na exigência de apreensão de um novo modelo econômico, o qual, nas palavras de Chaui (2007, p. 298), deve ser:

\footnotetext{
[...] destinado à redistribuição mais justa da renda nacional, de tal modo que não só diminua a excessiva concentração da riqueza e o Estado desenvolva uma política social que beneficie prioritariamente as classes populares, mas ainda implica o direito dessas classes de defenderem seus interesses tanto através de movimentos sociais, sindicais e de opinião pública, quanto pela participação direta nas decisões concernentes às condições de vida e de trabalho - nesse nível, a questão da cidadania é de justiça social e econômica.
}

Como bem reflete Sorto (2014, p. 21), "dividir as lutas para inserir as pessoas de modo mais efetivo é indispensável, mas o círculo onde todos os cidadãos deveriam estar é o mesmo, isto é, o lugar comum a todos os seres humanos independente de qualquer condição". A cidadania solidária se converte nesse instrumento de inclusão, que compreende os direitos e deveres que se coadunam à concepção mais ampla do desenvolvimento, exigindo-se um amplo comprometimento para a conquista dos direitos e a superação dos obstáculos que contrariem a democracia.

O contraponto diametral oposto da cidadania formal é, sem dúvidas, a cidadania solidária, por reconhecer a materialidade da cidadania e, identificando ainda o vínculo jurídico que liga cada um dos cidadãos ao Estado a qual pertence, ampliar essa vinculação para a ideia de comprometimento mútuo entre cada um dos sujeitos sociais, entre si e com o mundo, onde cada um é responsável pelo bem-estar e pela condição de realização da cidadania e da dignidade de todos os outros sujeitos.

É preciso, portanto, que a ideia de cidadania solidária seja reconhecida no contexto democrático pós-moderno como um ponto de partida de onde os direitos humanos, assegurados nos elementos da cidadania social tradicional, sejam o norte a conduzir o desenvolvimento das pessoas. Ser cidadão significa, portanto, ter alguns direitos e privilégios, e outros inúmeros deveres e obrigações, que vinculam cada um ao contexto sócio-político em que vive, correlacionando cada uma das pessoas entre si e com o mundo, seja nesse espaço territorial, seja em qualquer ponto do globo, nesta ou em outras gerações, pois a ideia de solidariedade não pode ser construída "[...] apenas para uma geração e planejado somente para os que estão vivos: deve transcender a duração da vida de homens mortais" (ARENDT, 1983, p. 64), configurando esse contexto global como a nova esfera pública, que determina o espaço para o aparecimento do ser humano à luz da cidadania solidária.

Na realidade, a cidadania solidária não pode apenas ser vislumbrada como um fim em si mesma. Ela deve ser compreendida como um meio para um fim e esse fim é a dignidade humana, cuja realização apenas pode ser possível com a construção de uma solidariedade real, que promova emancipação das pessoas, numa ideia de instrumentalização da participação política que possibilite o nascimento cidadão 
ou o segundo nascimento arendtiano, em que o agir, na esfera pública, agora global e solidariamente considerada, é comprometido com o outro, com a emancipação do outro, o que apenas é possível com a valorização da educação, como mote e instrumento de luta, refletindo a ideia de começo definitivo da vida humana na esfera pública.

\section{Conclusão}

A essa evidência, questiona-se: seria possível reconsiderar a cidadania sob o prisma da solidariedade de modo a, no contexto da esfera pública, serem reconstituídos os elementos civis, políticos e sociais em torno da ideia geral de bem-estar social, de modo a proporcionar a sua realização?

Pode-se, com certa conviç̧ão, afirmar que a realização plena dos direitos de cidadania envolve o exercício efetivo e amplo dos direitos humanos, o que, no âmbito do constitucionalismo moderno, significa dizer que a cidadania exercitada de maneira integral é, nada mais nada menos, do que o exercício de todos os direitos e garantias que são assegurados e são característica do Estado Democrático de Direito.

Muito mais importante do que a compreensão de uma cidadania solidária, em que a pedra de toque é o comprometimento, se faz curial o entendimento de que não será a discussão teórica que promoverá as mudanças necessárias à consecução dos objetivos constitucionais estabelecidos. É necessário que todos os cidadãos usufruam de cidadania e a vivam em sua plenitude.

A essa evidência, o aparecimento do homem no mundo (enquanto pressuposto da cidadania arendtiana ou segundo nascimento), deve ser revisto não apenas como uma simples atuação (ação e discurso) para que se promovam embates políticos, mas como compromisso com o bem-estar de todos em função de uma ideia de esfera pública reestruturada à luz da solidariedade.

Dessa forma, a reconfiguração da própria ideia clássica de cidadania deve ser pautada para além dos elementos civis, políticos, econômicos e sociais definidos por Marshall (1967). A partir de um aspecto mais amplo, a cidadania deve ser reconsiderada à luz da solidariedade, de modo a serem reconstituídos, no contexto da esfera pública, os próprios sujeitos sociais como partícipes primordiais do processo de promoção do bem-estar social.

A despeito de se reconhecer na cidadania um instrumento de luta, verifica-se que o seu papel histórico deve evoluir cada vez mais em torno da ideia dos direitos humanos, de modo a se efetivar, no plano da facticidade, os direitos e garantias mínimos que proporcionam ao ser humano a realização da ideia de dignidade que the confere identidade.

Desse modo, a esfera pública da cidadania apenas torna-se completa quando a solidariedade orienta as ações sociais e diretrizes públicas capazes de proporcionar a sua realização. Para tanto, podese reforçar a reflexão de que a cidadania solidária gera uma remodelagem total na estrutura social capaz de redimensionar todos os aspectos do desenvolvimento, promovendo melhorias consideráveis na vida de todas as pessoas e conferindo-lhes o valor dignidade que as torna únicas.

\section{Referências}

ARENDT, Hannah. A condição humana. 2. ed. Tradução de Roberto Raposo. Rio de Janeiro: Forense Universitária, 1983.

BERTASO, João Martins. Cidadania e direitos humanos: um trânsito para a solidariedade. Florianópolis: Renovar, 2004.

BERTASO, João Martins. Fragmentos ecologizados de direitos humanos e cidadania. Revista do Instituto do Direito Brasileiro - RIDB, Lisboa, v. 1, n. 7, p. 3861-3893, 2012. Disponível em: <http:// www.idb-fdul.com/>. Acesso em: 11 maio 2017. 
BLOCH, Ernst. Derecho natural y dignidad humana. Tradução de Felipe Gonzalez Vicén. Madrid: Dykinson, 2011.

BOBBIO, Norberto. Três ensaios sobre a democracia. Tradução de Sergio Bath. São Paulo: CardimAlario, 1991.

BOTTOMORE, Tom. Ciudadania y classe social, cuarenta años después. In: MARSHALL, T. H.; BOTTOMORE, Tom. Ciudadanía y clase social. Tradução de Pepa Linares. Madrid: Alianza, 2007. p. 85-138.

CHAUI, Marilena. Cultura e democracia: o discurso competente e outras falas. 12. ed. São Paulo: Cortez, 2007.

CHRISTENSON, Reo M. et al. Ideologias e política moderna. Tradução de Aydano Arruda. São Paulo: IBRASA, 1974.

CLARKE, Paul Barry. Ser ciudadano: conciencia y práxis. Tradução de Javier Eraso Caballos. Madrid: Sequitur, 2010.

DUMONT, Louis. O individualismo: uma perspectiva antropológica da ideologia moderna. Tradução de Álvaro Cabral. Rio de Janeiro: Rocco, 1985.

LECA, Jean. Preguntas sobre cidadania. In: MOUFFE, Chantal (Ed.). Dimensiones de la democracia radical: pluralismo, ciudadanía, comunidad. Trad. Gabriel Menino. Buenos Aires: Prometeo Libros, 2012. p. 31-48.

MARSHALL, T. H. Cidadania, classe social e status. Tradução de Meton Porto Gadelha. Rio de Janeiro: Zahar, 1967.

NUSSBAUM, Martha C. Las fronteras de la justicia: consideraciones sobre la exclusión. Tradução de Ramon Vilà Vemis; Albino Santos Mosquera. Barcelona: Paidós, 2012.

SANTOS, Boaventura de Sousa. Produzir para viver: os caminhos da produção não capitalista. Rio de Janeiro: Civilização Brasileira, 2002.

SANTOS, Wanderley Guilherme dos. 0 paradoxo de Rousseau: uma interpretação democrática da vontade geral. Rio de Janeiro: Rocco, 2007.

SEN, Amartya. Desenvolvimento como liberdade. Tradução de Laura Teixeira Mota. São Paulo: Companhia das Letras, 2005.

SILVEIRA, Rosa Maria Godoy. 500 anos de uma cidadania excludente. In: ZENAIDE, Maria de Nazaré Tavares; DIAS, Lúcia Lemos (Org.). Formação em direitos humanos na universidade. João Pessoa: UFPB, 2001. p. 115-118.

SORTO, Fredys Orlando. Apresentação. In: CRUZ, Lindalva Alves. Construção da cidadania das mulheres trabalhadoras rurais no Piauí. 2. ed. Teresina: Autor, 2014. p. 15-23.

Recebido em: 19/05/2016.

Aprovado em: 11/05/2017. 